\title{
ESTUDOS SOCIAIS DA CIÊNCIA E TECNOLOGIA E ENGaJAMENTO: Novas TENDÊNCIAS ${ }^{1}$
}

\author{
Alexandre Meloni Vicente ${ }^{2}$
}

\begin{abstract}
RESUMO
0 foco deste trabalho são os Estudos Sociais da Ciência e Tecnologia (ESCT), particularmente as discussões sobre Participação Pública e Democratização da Ciência. Sua motivação foi a percepção de uma tendência, dentro do campo, de abandono de uma posição estritamente investigativa e de exterioridade assumida em relação aos processos estudados. A produção recente dos ESCT evidencia não somente a preocupação em informar o público sobre as incertezas e negociações que caracterizam os processos científicos, mas também um esforço em contribuir para a discussão sobre questões práticas, sobre como as tecnologias devem ser construídas e como as controvérsias científicas devem ser resolvidas. Tal esforço pode representar uma aproximação entre o campo dos ESCT, a camada política e os movimentos sociais.
\end{abstract}

Palavras-Chave: Ciência. Tecnologia e sociedade. Ativismo.

\footnotetext{
${ }^{1}$ Uma versão preliminar deste trabalho foi apresentada no XXIX Congreso Latinoamericano de Sociología, Santiago de Chile, 2013.

${ }^{2}$ Doutorando pelo Departamento de Política Científica e Tecnológica do Instituto de Geociências da Universidade Estadual de Campinas, Brasil.xan.meloni@gmail.com
} 


\title{
SOCIAL STUDIES OF SCIENCE AND TECHNOLOGY AND ENGAGEMENT: NEW TRENDS
}

\begin{abstract}
Social studies of science and technology (Estudos Sociais da Ciência e Tecnologia ESCT), particularly discussions about public participation and the democratization of science, are the focus of this work. The study's motivation was the perception of a trend within the field to abandon a strictly investigative position and to assume externality with respect to the processes studied. ESCT's recent production is evidence of not only a concern about informing the public of the negotiations and uncertainties that characterize the scientific process but also an effort to contribute to the discussion of practical issues, of how technologies should be constructed and of how scientific controversies must be resolved. Such an effort may represent a connection between the field of ESCT, the political layer and social movements.
\end{abstract}

Keywords: Science. Technology and society. Activism.

\section{INTRODUÇÃO}

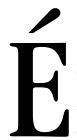
impossível deixar de notar os avanços no campo dos Estudos Sociais da Ciência ${ }^{3}$. Pouco restou da abordagem internalista mertoniana, na que o que havia para se explicar não era o método ou o conhecimento científico, mas somente a dinâmica e a posição social da empreitada científica na sociedade. A ciência deixou de ser vista como "pura" e imparcial, como uma cultura autônoma, dotada de acesso privilegiado à natureza, para ser caracterizada como um processo social. 0 interesse excessivo na comunidade científica e em seu alto grau de autonomia deu lugar às preocupações com a relação entre a produção científica e a sociedade, de maneira mais ampla. 0 foco de análise passou a ser, portanto, a ciência em si, e não somente os usos do saber científico nas instituições sociais. Trata-se, segundo Collins e Evans (2002), de trazer fatores "extra-científicos" para o debate científico-tecnológico.

o construtivismo caracterizou o conhecimento científico como socialmente criado ou construído (COLLINS; PINCH, 1979) e desafiou, através de investigação sociológica, a premissa considerada positivista ${ }^{4}$ da autoridade científica como

\footnotetext{
${ }^{3} 0$ campo passou posteriormente a ser conhecido como Estudos Sociais da Ciência e Tecnologia (ESCT).

${ }^{4}$ Termo utilizado por Martin e Richards (1995).
} 
formadora de opinião e palavra final nos debates científico-tecnológicos, independente de condições históricas, sociais ou culturais. A conclusão de uma controvérsia científica passou a ser entendida, portanto, resultado não de testes rigorosos realizados exclusivamente no âmbito científico, mas de pressões e demandas da comunidade, que refletiam não somente 0 conhecimento aceito por essa comunidade, mas também seus interesses e objetivos sociais. Foi descartada, deste modo, a premissa de que seria final a palavra dos cientistas e "experts", imparciais e livres de qualquer contaminação de ordem política ou social, sobre aspectos técnicos e tomada de decisões em qualquer assunto que envolvesse ciência e/ou tecnologia.

A recusa da ideia de que a resolução das controvérsias científicas se dava somente baseada em conceitos de verdade e eficácia e na autoridade científica abriu espaço para as discussões sobre a participação do público leigo, e alguns pontos se tornaram centrais. Primeiro, é pressuposto nas sociedades democráticas que todas as decisões devem ser, senão totalmente, o máximo possível públicas. São as exceções a esta regra que devem ser justificadas devidamente. Segundo, a participação pública é necessária para confirmar ou contestar não somente as decisões, mas também a relevância das questões que são ou deveriam ser tratadas pela comunidade científica. Por fim, o saber científico é construído e praticado dentro de instituições, e o grande poder de algumas dessas instituições pode leválas a tentar manipular informações e impor decisões, caso não sejam continuamente contestadas e criticadas pela opinião pública (JASANOFF, 2003). 0 conhecimento científico só se torna socialmente aceito quando envolve, além de um extenso grupo de experts, os possíveis usuários e o público considerado leigo. Sua validade é testada não somente dentro de laboratórios, mas sim em um mundo em que fatores sociais, econômicos, culturais e políticos moldam os produtos e os processos resultantes da inovação científico-tecnológica.

Das premissas construtivistas surge a noção de que uma maior participação pública, nas tomadas de decisão relativas a assuntos de natureza técnica, melhora o valor público e a qualidade da ciência e da tecnologia. Um modelo participativo seria um grande progresso em relação a modelo "decidir, anunciar, defender", pois este último requer muito mais tempo, aliena o público, e produz recomendações uniformes (FUTRELL, 2003). Exercícios de participação pública costumam obter mais êxito, pois seus participantes representam a população, são independentes, envolvidos desde o início no processo decisório, possuem influência na comunidade local, prezam pela transparência no processo, têm acesso aos recursos, e possuem tarefas definidas (ROWE; MARSH; FREWER, 2004). 
Paralelamente, surge o conceito de core set, caracterizado como o grupo ou os grupos de indivíduos dotados de autoridade para opinar e até mesmo decidir uma controvérsia. Collins (1992) discorre detalhadamente sobre as estratégias utilizadas pelos membros de um core set para enfraquecer seus oponentes, que englobam críticas técnicas à qualidade do trabalho científico, dúvidas quanto às capacidades experimentais e honestidade dos experimentos, avaliações de reputação, que levam em conta 0 prestígio da instituição que abriga os pesquisadores, o histórico de sucessos e falhas, e aspectos de personalidade e inteligência. As controvérsias apresentam, portanto, uma flexibilidade interpretativa. Materiais, dados, métodos e ideias podem possuir as mais diferentes interpretações para diferentes posições dentro de um debate. Julgamento e Interpretação são, deste modo, conceitos chave, e codependentes; e as controvérsias são resolvidas através de ações que definem uma posição particular como racional e correta aos olhos da comunidade científica.

Inicialmente voltados para os debates de ordem técnica, travados quase que exclusivamente dentro da comunidade científica, os estudiosos do core set passaram a preocupar-se também com a inclusão de grupos externos a ela, provenientes do público em geral. Participação pública e democratização da ciência se tornam, juntamente com a construção social do conhecimento científico, os assuntos principais das pesquisas do campo. A constituição do conhecimento científico depende, portanto, de configurações sociais particulares.

Os ESCT atualmente englobam duas amplas correntes teóricas principais. A primeira consiste na pesquisa sobre a natureza e as práticas da Ciência e Tecnologia (C\&T), tratadas como instituições sociais dotadas de distintas estruturas, compromissos, práticas e discursos que variam de acordo com 0 tempo e com as diferentes culturas. Esta linha de pensamento atenta para questões como o método científico, a credibilidade dos fatos científicos e a emergência de novas disciplinas. A segunda se concentra mais nos impactos e no controle da C\&T, com foco especial nos riscos oferecidos à segurança, à democracia, à paz, às comunidades, ao desenvolvimento sustentável e aos valores humanos. Suas análises são motivadas por questões como as prioridades no financiamento de pesquisas, a participação de diferentes grupos nos processos decisórios, a medição de riscos e benefícios ligados à C\&T, e a comunicação entre a comunidade científica e o público.

Porém, enquanto muito se discute sobre a participação dos experts e do público leigo nos processos decisórios, ainda pouca atenção é dada sobre como 
deve ser a participação do próprio sociólogo ${ }^{5}$ da ciência. Isto porque a maior parte das análises, que constituem o "Alto Clero"6 do campo, é ainda pautada em princípios metodológicos de imparcialidade e neutralidade, provenientes da corrente denominada Sociologia do Conhecimento Científico (SSK, do inglês Sociology of Scientific Knowledge), em particular do Programa Forte da Escola de Edimburgo; e da chamada Teoria Ator-Rede (ANT, do inglês Actor-Network Theory), que postula a exterioridade dos investigadores em relação aos problemas estudados (LATOUR, 2005).

\section{CONHECIMENTO E INTERVENÇÃO}

0 Alto Clero manteve seu foco na interpretação da ciência e tecnologia e desenvolveu um sofisticado arcabouço conceitual para explorar o processo de construção do conhecimento, mas não podemos menosprezar a importância do "Baixo Clero", menos preocupado com o entendimento da ciência e tecnologia per se, e mais concentrado em adaptar o conhecimento científico-tecnológico ao interesse público. Focados em reforma e ativismo, os pesquisadores de tal corrente abordam criticamente assuntos que envolvem política, governança e financiamento, bem como os aspectos da ciência e tecnologia mais relevantes para o público em geral. Mais que isso, eles procuram reformar o conhecimento científico-tecnológico tendo em vista a igualdade, o bem estar e o meio ambiente, desafiando as estruturas que permitiram aos físicos nucleares contribuírem para 0 desenvolvimento de armas atômicas, que permitiram aos químicos se envolver em uma série de projetos desastrosos para o meio ambiente, ou que deram à Biologia uma posição central na industrialização da agricultura. Tais estudiosos enxergam o entendimento da natureza social do conhecimento científico como indissociável da promoção de uma ciência socialmente responsável.

Para o Baixo Clero, as questões centrais estão ligadas à reforma, à promoção de um conhecimento científico que beneficia o público em geral. Como podem as decisões técnicas ser tomadas através de processos genuinamente democráticos? Podem as inovações ser democraticamente controladas? Como as novas tecnologias devem ser regulamentadas? Até que ponto elas podem ser consideradas entidades políticas? Quais são as dinâmicas das controvérsias técnicas, e como os diferentes grupos envolvidos procuram controlar suas

\footnotetext{
5 Para fins práticos, o termo "sociólogo" aqui, mesmo quando utilizado sozinho, está sempre associado aos pesquisadores do campo da Sociologia da Ciência e Tecnologia.

${ }^{6}$ Termo utilizado por Sismondo (2008).
} 
resoluções e os participantes relevantes? (SISMONDO, 2008). Como podem os estudos em Ciência, Tecnologia e Sociedade ter valor para os ativistas? (HESS et al., 2008).

A opção por uma investigação politicamente engajada evidencia três dificuldades principais: a primeira diz respeito aos temas a serem estudados, que obrigam uma relação com organizações e movimentos sociais, dificultada pelas próprias condições institucionais de organização da investigação; a segunda é a dificuldade de conseguir financiamento para investigações sobre temas suscetíveis de entrar em conflito com interesses econômicos privados ou de Estado; a terceira é resultado da avaliação assimétrica das pesquisas orientadas para interesses do Estado ou de empresas, notadamente melhor financiadas e pouco questionadas sobre suas implicações, e as investigações visando os movimentos sociais e 0 interesse público, muito mais sujeitas a acusações de panfletarismo político e ideológico (NUNES, 2007).

Não obstante, Woodhouse et al. (2002) afirmam que é crescente o número de pesquisadores dos ESCT que procuram expressar seus valores sociais e preocupações políticas sem entrar em conflito com os desenvolvimentos conceituais do campo. Este fenômeno, denominado pelos autores de reconstrutivismo ${ }^{7}$, direciona seus esforços na promoção de uma civilização mais democrática, ambientalmente sustentável, e socialmente justa; e é caracterizado pelos esforços deliberados dos estudiosos em estruturar suas descrições e explicações para servir a propósitos sociais, seja documentando e condenando falhas anteriores, seja propondo novas alternativas. Por ser algo relativamente novo e ainda pouco explorado, estes autores propõem quatro tópicos que contribuiriam para o melhor aproveitamento do que chamam "uma nova oportunidade":

- Discussões sobre a importância de se incorporar intenções normativas, ativistas ou reconstrutivistas nas pesquisas;

- Análises sobre tópicos que não recebem a devida atenção, e um processo de formulação de compromissos profissionalmente sofisticado;

- Participação mais ativa em esforços visando moldar as atividades tecnocientíficas em direções progressivas;

\footnotetext{
${ }^{7}$ Definido pela intenção geral de conduzir pesquisas com objetivos de informar ou ilustrar 0 público leigo, e participar das deliberações e negociações democráticas que moldam e modificam as tecnologias (WOODHOUSE et al., 2002).
} 
- Análises reflexivas sobre as práticas de publicação, o sistema de recompensas, e a própria fundação conceitual dos Estudos sobre ciência e tecnologia.

Argumentam os autores que os estudos politicamente engajados podem ser especialmente importantes em situações em que interesses comerciais são protegidos em demasia, ou em que grupos privilegiados recebem tratamento diferenciado em detrimento a inúmeros outros interessados. Mais do que apontar desigualdades, tais pesquisadores buscam, ou deveriam buscar, desafiar tecnologias problemáticas, prover assistência analítica e credibilidade aos grupos marginalizados e às "vozes esquecidas", e articular alternativas.

A credibilidade dos grupos marginalizados é um ponto crucial. Muitos deles, embora bem representados numericamente, não possuem a expertise considerada necessária tanto para fundamentar suas reivindicações de forma concisa e convincente, quanto para responder às críticas de modo satisfatório. Utilizando sua expertise em prol de tais grupos, o sociólogo da ciência lhes confere uma autoridade cientificamente aceita, aumentado suas possibilidades de participação no processo decisório.

Outro ponto abordado diz respeito às pesquisas negligenciadas, entre as quais as terapias de saúde alternativas são um bom exemplo. Graças, em grande parte, ao predomínio do financiamento privado, pesquisas sobre os riscos à saúde causados por uma serie de compostos químicos são escassas, notadamente no que diz respeito a poluentes ambientais. Quanto aos tratamentos, os pacientes frequentemente são informados sobre os mais convencionais, com altos níveis de toxinas - especialmente rádio e quimioterapia, nos casos de câncer - e chances moderadas de sobrevivência, enquanto pouca atenção é dada à medicina alternativa. 0 conhecimento sobre substâncias botânicas e terapias mente-corpo, por exemplo, permanece, deste modo, limitado. Pesquisas direcionadas para interações entre ambiente e estilo de vida também recebem pouca importância e financiamento, em parte pela manutenção de interesses industriais. Tais pesquisas podem apresentar terapias de extrema importância para grande parte da população, e deve ser preocupação do pesquisador engajado a análise e publicação das diferenças entre 0 conhecimento necessário e 0 conhecimento disponibilizado.

Alguns outros exemplos, de ordem mais particular, também são apresentados, como a pesquisa de Sharon Beder sobre o sistema de esgotos de 
Sydney, que incluía dados não informados sobre poluição e críticas ao sistema de engenharia sanitária, e contribuiu para manifestações ambientais. Ou o trabalho de Todd Cherkasky sobre a introdução de novas tecnologias na indústria panificadora, que apresentava intenções explicitas de apoio aos sindicatos e desenvolvimento de estratégias para proteção de empregos e melhora das condições de trabalho. David Noble, em seus estudos sobre a introdução de tecnologias nos locais de trabalho, procurou revelar o impacto negativo do capitalismo na condição dos trabalhadores e incentivar sua mobilização. As análises de Richard Sclove sobre as conexões entre democracia e tecnologia clamavam por maior participação popular nos processos decisórios sobre ciência e tecnologia (WOODHOUSE et al., 2002).

No caso da América Latina, podemos citar o trabalho de Herrera (1981), que argumenta que as tecnologias então em uso nos países menos desenvolvidos do continente foram geradas dentro de um paradigma originado nos países de capitalismo avançado, não sendo, portanto, adequadas para promover 0 desenvolvimento de países periféricos. Seu trabalho busca orientar a geração de tecnologias apropriadas para as áreas rurais e contribuir para a construção de um novo sistema, mais adequado às necessidades e condições das sociedades periféricas.

Collins e Evans (2002) também contribuem, embora de forma menos direta, para a discussão. Ao englobar 0 sociólogo da ciência na categoria Interactional Expertise, os autores o caracterizam como um indivíduo apto não só a realizar análises sociológicas, mas também a interagir de forma eficaz com os participantes de seu objeto de estudo.

No contexto dos ESCT, o campo de estudos inclui diversas estratégias de pesquisa e campos de exposição, tais como presença em conferências, laboratórios, escolas e colóquios, entrevistas com um vasto número de pessoas associadas com a comunidade, consulta de uma vasta literatura técnica, trabalhos em arquivos, relações com informantes, contato com 0 público leigo para assimilar suas percepções sobre a comunidade científica e sobre a tecnologia, tornar-se membro de organizações e movimentos sociais, muitas vezes de forma ativa e preocupada, entre outros. Deste modo, com o tempo, o sociólogo desenvolve uma competência notável nos aspectos técnicos de ciência e tecnologia envolvidos, entendendo o conteúdo e a linguagem do campo, suas terminologias, teorias, realizações, métodos e controvérsias; podendo então realizar suas análises com respeito às relações sociais, estruturas de poder, significados culturais, e história do objeto estudado (HESS, 2001). 
Isto se torna particularmente relevante quando consideramos que o tempo da política, pressionado pela opinião pública, aglomera aspectos éticos e científicos em processos que necessitam rapidez na decisão, enquanto o tempo da ciência funciona em um compasso lento e prudente. $\mathrm{E}$ as decisões precisam ser tomadas, geralmente, antes que um consenso científico tenha sido alcançado.

Um bom exemplo deste processo é o caso da Lei de Biossegurança no Brasil. Durante a tramitação do projeto, deputados ligados à Igreja Católica procuraram retirar 0 artigo sobre células-tronco embrionárias, após o pedido da Conferência Nacional dos Bispos do Brasil. Durante a votação do projeto na Câmara, estavam presentes membros da Associação Brasileira de Distrofia Muscular, e do Movimento em Prol da Vida. Pessoas que sofriam de degeneração progressiva do tecido muscular e familiares de portadores de doenças neurológicas, tais como Mal de Parkinson e Mal de Alzheimer, que podem ser beneficiados pelas pesquisas com células-tronco, também pressionaram pela aprovação da lei. Conscientes da capacidade terapêutica das pesquisas em biotecnologia, os poderes legislativo e judiciário não ignoram os limites das descobertas científicas, mas são constantemente assediados pelos interesses econômicos das próprias pesquisas, e pelos interesses morais de determinados setores da sociedade, assim como pelos interesses da própria comunidade científica. A permissão legal para pesquisas ligadas à biotecnologia, portanto, envolveu uma discussão pública, técnica, política, jurídica, religiosa e científica, em um processo que durou quase cinco anos. Pode parecer muito, mas é um tempo muito menor do que a ciência necessita para definir, com segurança, todos os riscos e benefícios deste tipo de pesquisa (OLIVEIRA, 2008).

0 público espera por verdades conclusivas, mas a ciência aponta para teses e hipóteses provisórias, que podem ser confirmadas, refutadas ou transformadas, à medida que 0 conhecimento científico é construído. Enquanto isso, diferentes interesses de diferentes grupos clamam por regulamentação e ordenamento jurídico deste conhecimento, sobretudo quando ele possui implicações éticas. Neste panorama de incertezas, o diálogo entre a comunidade científica e o público é essencial, e tanto as possibilidades benéficas das pesquisas como seus possíveis riscos devem ser conhecidos por todos os participantes. E o sociólogo, através da competência adquirida em seus estudos sobre ciência e tecnologia, pode desempenhar de forma competente o papel de interlocutor nestes diálogos, por sua capacidade de interagir tanto com o público quanto com os experts. 


\section{ENGAJAMENTO EM PRÁTICA}

Collins e Evans (2002) não chegam a entrar na discussão sobre até que ponto produção de conhecimento e intervenção política podem caminhar juntos no campo dos ESCT, mas Nunes (2007) o faz, afirmando que podem, e devem.

0 autor utiliza-se de exemplos da União Européia, onde investigadores dos ESCT prestam aconselhamento em comissões para políticas públicas, sobretudo em questões que envolvem relações entre modos de governar, formas do exercício da cidadania, e perspectivas, ligadas aos avanços científicos e tecnológicos, de uma melhor qualidade de vida no futuro. Mas seu principal exemplo vem do Brasil.

Em 1976, escreve ele, ainda sob a ditadura militar, Sérgio Arouca defendia, na Universidade Estadual de Campinas, sua tese de doutorado O Dilema Preventivista: Contribuição para a Compreensão e Crítica da Medicina Preventiva. 0 objetivo geral era, a partir da análise do programa e das propostas de organização da medicina preventiva, criticar suas relações com a organização do Estado e da economia capitalista, e lançar as bases de uma teoria social da saúde. Arouca, militante comunista e opositor da ditadura, viria a ser consultor da Organização Panamericana de Saúde, presidente da Fundação de Investigação Oswaldo Cruz, Deputado Federal, Secretário Estadual e Municipal de Saúde do Rio de Janeiro e Secretário Nacional da Gestão Participativa do Ministério da Saúde no Brasil. Sua tese constituiu uma das principais referências teóricas que alimentaram a reconstrução da saúde pública no Brasil e sua redefinição como saúde coletiva:

A trajectória intelectual, profissional e política de Sérgio Arouca condensa de maneira exemplar as dinâmicas de coconstrução de uma área do saber, a Saúde Colectiva - ela própria o culminar de mudanças institucionais em curso no mundo acadêmico desde a década de 70 - de políticas públicas e de intervenções institucionais e de formas de acção colectiva... Esse intenso trabalho de renovação intelectual e científica viria a influenciar a convergência de profissionais de saúde e de cientistas sociais no chamado Movimento Sanitarista (NUNES, 2007, p. 20).

A redefinição histórica e processual do campo da saúde, derivada da tese de Arouca, afirmava a indissociabilidade da produção de conhecimento e da intervenção baseada em procedimentos participativos, e viria a influenciar a 
criação e organização de um Sistema Único de Saúde, pautado na Constituição de 1988, que define a saúde como "direito de todos e dever do Estado".

Outro caso que constitui um claro exemplo de intervenção dentro dos ESCT é relatado por Lynch e Cole (2005), e diz respeito ao processo penal "Povo contra Hyatt", ocorrido nos Estados Unidos da América em 2001, onde o próprio Simon Cole, um dos autores, foi chamado a depor como testemunha de defesa. James Hyatt havia sido acusado de cometer um roubo em Nova York, e suas impressões digitais, encontradas no local, eram a única evidência apresentada pela acusação. A expertise de Cole era baseada em sua pesquisa sobre a impressão digital como evidência criminal, amplamente aceita, desde 0 início do século XX, como confiável, ou mesmo infalível, nos tribunais da maior parte do mundo. 0 dogma de que não existem dois indivíduos com impressões digitais iguais veio acompanhado da confiança nos examinadores de tais provas, sem questionamentos sobre as taxas de erros e outros dados estatísticos. Dogma baseado em uma visão positivista, da ciência como objetiva e pura. Minar esta visão positivista e caracterizar o conhecimento científico como socialmente criado ou construído resultaria no enfraquecimento deste dogma. 0 intuito do advogado de defesa, a chamar Cole como testemunha, era restringir a admissibilidade da ciência forense (no caso, a impressão digital) no tribunal.

Enquanto um técnico perito em impressões digitais é levado a acreditar na infalibilidade de seu trabalho, baseado na pureza da ciência, um estudioso dos ESCT é capaz de problematizar esta suposta pureza com certa autoridade. Cole foi, portanto, chamado a depor não somente por seu conhecimento específico sobre identificação de impressões digitais, resultante de sua imersão em tal assunto, mas também por sua expertise mais geral, como sociólogo da ciência.

Para finalizar, cito um exemplo brasileiro mais atual, do Grupo de Análise de Políticas de Inovação da UNICAMP (GAPI), cujos esforços são voltados para 0 entendimento da relação entre tecnologia e exclusão social, bem como para a necessidade de uma tecnologia que promova a inclusão. Seus trabalhos têm como foco 0 processo de desenvolvimento de uma tecnologia para a inclusão social, denominada Tecnologia Social $(\text { TS })^{8}$, através de um processo que envolve a participação direta dos interessados em seu desenvolvimento e sua interação com os atores tradicionalmente ocupados em concebê-la, notadamente a comunidade de pesquisa. Segundo Dagnino (2010), o objetivo do grupo é auxiliar a elaboração

${ }^{8} 0$ termo compreende "produtos, técnicas e/ou metodologias replicáveis, desenvolvidas na interação com a comunidade e que representem efetivas soluções de transformação social" (RODRIGUES; BARBIERI, 2008, p. 1070). 
de políticas voltadas para a inclusão, proporcionando aos professores, pesquisadores, movimentos sociais e à camada política, um insumo para geração de conhecimento para a inclusão social.

0 GAPI se insere em um conjunto de grupos latino-americanos que procura assinalar demandas cognitivas e propor soluções tecnológicas através da interface entre academia, movimentos sociais, comunidades locais e órgãos governamentais. Os esforços destes grupos são orientados para a satisfação de demandas:

[...] colocadas pelo objetivo da inclusão social, mediante metodologias de trabalho especialmente concebidas para combinar capacidades e iniciativas em áreas como a agricultura familiar, habitação popular, energias alternativas, reciclagem de resíduos, produção e conservação de alimentos, entre muitas outras (DAGNINO, 2010, p. 8).

Ainda, segundo o autor, a participação plena dos usuários é indispensável no processo de construção do conhecimento. Tais demandas cognitivas só podem ser devidamente expressas pelo excluídos, e adequadamente equacionadas caso eles possuam as habilidades políticas e cognitivas necessárias para se relacionar satisfatoriamente com os outros atores envolvidos.

Os problemas sociais não devem, portanto, ser postulados a priori. Sua identificação depende do contato com atores tais como os movimentos sociais e as comunidades e organizações locais, possibilitando uma construção coletiva de conhecimento que incorpore os valores, interesses e saberes dos excluídos. É através das contribuições das últimas três décadas do campo dos ESCT, além de outras abordagens interdisciplinares nas áreas de história, economia, sociologia e filosofia sobre a relação entre Ciência, Tecnologia e Sociedade, que o grupo busca alcançar esta construção coletiva de conhecimento, e propor um marco analíticoconceitual para abordar a TS como algo em processo de construção, que engloba uma diversidade de atores e ideias surgidas e disseminadas dentro de um panorama de contestação da Tecnologia Convencional. Destacam-se contribuições teóricas que enfocam a relação Ciência-Tecnologia-Sociedade e que, mesmo não diretamente ligadas ao movimento da TS, estão relacionadas a um conjunto de indicações de caráter sociotécnico com intuito de orientar ações alternativas de desenvolvimento científico e tecnológico. 
Os trabalhos do GAPI, portanto, possuem enfoque interdisciplinar, balizado pelos ESCT, e são orientados por questões práticas, visando a elaboração de políticas públicas. Muitas vezes apresentam experiências de desenvolvimento de tecnologias alternativas, principalmente relacionadas à habitação, produção de alimentos e, mais recentemente, às iniciativas no campo da agroecologia, que vem recebendo crescente apoio de movimentos sociais (DAGNINO, 2010).

Evidencia-se, por estes exemplos, uma crescente importância dada ao engajamento e ao ativismo, resultante de uma nova concepção e percepção das condições da intervenção pública dos ESCT, da relação entre conhecimento e intervenção e de sua legitimação. Seja propondo mudanças de ordem técnica e política, servindo de porta voz para grupos menos privilegiados, prestando aconselhamento em comissões para políticas públicas, ou mesmo intermediando os debates entre experts e publico leigo, percebemos a multiplicação de um novo tipo de sociólogo da ciência, menos preocupado com os princípios de neutralidade e imparcialidade, e politicamente engajado.

\section{CONCLUSÕES}

Não foi tarefa fácil interrogar a suposta pureza e imparcialidade da ciência, seu acesso privilegiado à natureza; indagar sua autoridade, abalar seu status de verdade e superioridade; caracterizar o conhecimento científico como socialmente criado ou construído, dependente de condições históricas, sociais ou culturais, possibilitando os estudos sobre Participação Pública e Democratização da Ciência. Foram necessárias décadas de análises e debates para que os ESCT reivindicassem, baseados em observações e investigações empíricas da ciência como atividade social, sua autoridade e sua institucionalização como um novo campo de estudos interdisciplinar. Seu mérito é digno de reconhecimento.

Não obstante, uma pergunta deve estar sempre presente quando analisamos criticamente não somente nosso campo de estudos, mas a nós mesmo, como sociólogos da ciência e tecnologia: Podemos fazer mais? Podem nossos estudos ter valor para os ativistas e movimentos sociais?

A literatura, embora ainda pouco numerosa, sobre ativismo e engajamento político dentro dos ESCT indica que sim. Tal literatura engloba tópicos de importância política clara, colocando as relações entre ciência, tecnologia e interesse público no centro do programa de pesquisa. Deste modo, o Baixo Clero transformou a interação entre conhecimento científico-tecnológico, política e interesses públicos, normalmente tratada como um contexto de estudos, em um 
tópico de pesquisa dentro dos ESCT. A política se torna um objeto de estudos, ao invés de um modelo de análises.

As experiências relatadas mostram que o sociólogo da ciência pode, através das habilidades e competências adquiridas nos estudos e análises sobre os mais diversos campos científicos, não somente contribuir empírica e teoricamente para uma literatura fora dos ESCT, mas também para identificar fenômenos, significados, interpretações e relações sociais que por vezes passam despercebidos pela comunidade científica e pela camada política; possibilitando-o opinar de forma competente sobre a formulação e implementação de políticas públicas.

Ademais, os conhecimentos sobre ciência e tecnologia, e sobre as particularidades técnicas de campos de estudo específicos, quando somados às competências sobre cultura, interesses e sociedade necessárias aos estudos sociais, fazem do sociólogo da ciência um interlocutor altamente capacitado a intermediar os debates entre campos específicos de pesquisa e o público em geral.

Seja como for, sua participação, como agente ativo e participativo politicamente, e como suporte para criação e avaliação de novas políticas públicas, pode trazer benefícios ao processo decisório.

Podemos, portanto, ir além da imparcialidade e neutralidade dos SSK (Sociology of Scientific Knowledge), da exterioridade postulada pela Teoria AtorRede, da retórica, e focar diretamente nos problemas, conflitos e contradições decorrentes do avanço científico. Podemos ir além das observações e estudos que demonstram como a ciência e a tecnologia são socialmente construídas. Podemos sugerir como elas podem ser melhoradas.

\section{REFERÊNCIAS}

COLLINS, Harry M. Changing order: replication and induction in scientific practice. Chicago: University of Chicago Press, 1992.

COLLINS, Harry M.; EVANS, Robert. The third wave of science studies: studies of expertise and experience. Social Studies of Science, London, v. 33, n. 2, p. 235296, 2002.

COLLINS, Harry. M.; PINCH, Trevor J. The construction of the paranormal: nothing unscientific is happening. In: WALLIS, Roy (Ed.). On the margins of science: the social construction of rejected knowledge. Keele: University of Keele, 1979. p. 237270 . 
DAGNINO, Renato (Org.). Tecnologia social: ferramenta para construir outra sociedade. Campinas: Komedi, 2010.

FUTRELL, Robert. Technical adversarialism and participatory collaboration in the U.S. Chemical Weapons Disposal Program. Science, Technology \& Human Values, London, n. 28, n. 4, p. 451-482, 2003.

HERRERA, Almircar. The generation of technologies in rural areas. World Development, Oxford, v. 9, n. 1, p. 21-35, jan. 1981.

HESS, David J. et al. Science, Technology, and Social Movements. In: HACKETT, Edward J. (Ed.). The handbook of science and technology. Cambridge: MIT Press, 2008. p. 473-498.

HESS, David J. Ethnography and the development of science and technology studies. In ATKINSON, Paul. et al. Handbook of ethnography. London: Sage, 2001. p. 234-245.

JASANOFF, Sheila. Breaking the waves in science studies: comment on H. M. Collins and Robert Evans, 'The third wave of Science Studies'. Social Studies of Science, London, Sage Publications, v. 33, n. 3, p. 389-400, 2003.

LATOUR, Bruno. Reassembling the social: an introduction to actor network theory. Oxford: Oxford University Press, 2005.

LYNCH, Michael; COLE, Simon. Science and technology studies on trial: dilemmas of expertise. Social Studies of Science, London, v. 35, n. 2, p. 269-311, 2005.

MARTIN, Brian; RICHARDS, Evellen. Scientific knowledge, controversy, and public decision-making. In: JASANOFF, Sheila et al. (Ed.). Handbook of science and technology studies. Newbury Park, CA: Sage, 1995. p. 506-526.

NUNES, João. A. A "viragem normativa" e a política dos estudos sobre a ciência. Coimbra: Centro de Estudos Sociais da Universidade Coimbra, 2007.

OLIVEIRA, José Aparecido. Zeus $x$ prometeu: o embate discursivo nos artigos favoráveis e contrários à pesquisa com células-tronco embrionárias. 2008. Dissertação (Mestrado em Comunicação Social) - Universidade Metodista de São Paulo, São Paulo, 2008.

RODRIGUES, Ivete; BARBIERI, José Carlos. A emergência da tecnologia social: revisitando o movimento da tecnologia apropriada como estratégia de desenvolvimento sustentável. Revista de Administração Pública, Rio de Janeiro, v. 42, n. 6, nov./dez. 2008. 
ROWE, Gene; MARSH, Roy; FREWER, Lynn. Evaluation of a deliberative conference. Science, Technology \& Human Values, London, v. 29, n. 4, p. 512556, 2004.

SISMOND0, Sergio. Science and technology studies and an engaged program. In: HACKETT, Edward J. et al. (Ed.). The handbook of science and technology studies. Cambridge: The MIT Press, 2008. p. 13-31.

WOODHOUSE, Edward et al. Science studies and activism: possibilities and problems for reconstructivist agendas. Social Studies of Science, London, v. 32, n. 2, p. 297-319, 2002. 